\title{
A importância da pergunta na educação filosófica da criança
}

\author{
The importance of question in child's philosophical education
}

Darcísio Natal Muraro ${ }^{1}$

\begin{abstract}
Resumo
Este trabalho tem por objetivo analisar o seguinte problema: em que condição a pergunta pode criar a experiência de filosofar? Argumentamos que a pergunta, como elemento vitalizador da experiência, é uma condição necessária para a criação da atividade filosófica e educativa. Isto porque a pergunta é a mente em atividade buscando significar a experiência num mundo conflituoso, provisório, instável, contestável e, assim, aberto à continua renovação. Por constituir-se numa investigação eminentemente conceitual sobre a trama da pergunta na experiência e aprendizagem da criança, adotamos a metodologia de análise conceitual no campo filosófico, lastrado por um procedimento bibliográfico. Desta forma, amparamos nossa análise nas contribuições de Platão acerca da origem da indagação filosófica, na filosofia da experiência de Dewey, e na pedagogia da pergunta de Freire. Estas referências corroboram para uma interpretação crítica e criativa acerca da pergunta que podem contribuir para um ethos da atividade de filosofar e educar.
\end{abstract}

Palavras-chave: Pergunta. Conceito. Experiência. Filosofar. Educar.

\begin{abstract}
This paper aims to analyze the following problem: under what condition can the question create the experience of philosophizing? We argue that the question, as a vitalizing element of experience, is a necessary condition for the creation of philosophical and educational activity. This is because the question is the active mind seeking to signify experience in a conflicting, provisional, unstable, contestable world, and thus open to continual renewal. As it is an eminently conceptual investigation of the question plot in the child's experience and learning, we adopted the methodology of conceptual analysis in the philosophical field, backed by a bibliographic procedure. In this way, we support our analysis of Plato's contributions about the origin of the philosophical inquiry, Dewey's philosophy of experience, and Freire's pedagogy of the question. These references corroborate a critical and creative interpretation of the question that may contribute to an ethos of philosophizing and educating activity.
\end{abstract}

Keywords: Question. Concept. Experience. Philosophize. Educate.

\footnotetext{
1 Professor Adjunto do Departamento de Educação da UEL e Programa de Mestrado em Educação. E-mail: murarodnm@gmail.com.

Interfaces da Educ., Paranaíba, v.10, n.30, p.414 - 438, 2019
}

ISSN 2177-7691 


\section{Introdução}

Este estudo se desenvolve a partir do campo de pesquisa da filosofia da educação. O problema que analisaremos tem a seguinte interrogação guia: em que condição a pergunta pode criar a experiência de filosofar? A questão trata do ensino de filosofia para/com crianças como problema eminentemente filosófico. Assim, a preocupação é aprofundar a compreensão acerca do papel formativo da filosofia na formação das crianças e jovens no enfrentamento dos desafios colocados para a educação e para a escola num mundo em rápida e profundas transformações sociais, econômicas, politicas e culturais.

As crianças estão expostas e são sensiveis aos apelos do consumismo, aos atrativos tecnológicos, sobretudo eletrônicos, a fascinação das midias digitais e redes sociais, ao acirramento dos conflitos sociais e políticos de toda ordem, ao agravamento dos problemas ecológicos, ao sistema econômico que gera concentração de renda e empobrecimento generalizado da população. Neste contexto, as crianças reagem com perguntas, querendo entender e agir neste conflituoso cenário. Suas perguntas podem ser respondidas pelos adultos que apelam ora para as crenças religiosas, ora para a ciência, ora para o senso comum. Elas dispõem, inclusive, de um poderoso amigo para responder a todas suas perguntas: o google.

Por sua vez, no campo educacional, as recentes reformas da legislação nacional como a Base Nacional Comum Curricular (BNCC) e os interesses politicos conservadores desqualificam a filosofia e advogam um ensino eminentemente científico, técnico e moralista atrelado aos interesses do mercado. Desprovida da reflexão crítica, esta educação prioriza o ensino de perguntas e respostas prontas que levam à superficialidade e à fragmentação do conhecimento, valorizando processos cognitivos mnemônicos que colocam a mente da criança numa situação passiva de recepção de conhecimento para atender a uma realidade de exigências fabricadas pelo sistema de ensino. 
A importância da pergunta na educação filosófica da criança. 416

As condições culturais que predominam na atual experiência da criança são bastante desfavoráveis para a atividade da filosofia. A crise que vivemos convoca a filosofia a pensar as perguntas que serão decisivas para a existência social e sobrevivência da própria filosofia. Paradoxalmente, entendemos que a avalanche de produtos tecnológicos e de conteúdos culturais não tem poder de eliminar completamente as perguntas de fundo da experiência das crianças. Assim, um dos problemas colocadas para a filosofia é o de pensar as possibilidades de uma educação para o perguntar filosófico no campo da educação básica nacional, especialmente nos níveis destinados às crianças.

\section{Metodologia}

Para desenvolver o problema colocado adotaremos como processo metodológico, de caráter qualitativo e bibliográfico, os procedimentos filosóficos de análise, articulação e atualização de conceito. Na primeira etapa, a pesquisa se ocupa em compreender a importância da pergunta na experiência socrática por meio da obra de Platão (2008a, 2008b, 2008c). Em seguida, analisaremos o entendimento de filosofia, destacando o papel do pensamento reflexivo inquiridor no pensamento de John Dewey (1940, 1979 e 1991). Por fim, recorremos à pedagogia da pergunta de Paulo Freire para pensar o problema filosófico em nosso contexto educacional.

Nosso estudo faz um recorte metodológico em torno de três pensadores que se ocuparam de pensar o problema da pergunta para a filosofia e para a educação. A Paideia grega se desenvolve por meio das perguntas conduzidas por Sócrates nos diálogos de Platão, a filosofia da experiência de Dewey coloca o problema da pergunta como problema central para atividade reflexiva crítica, e a pedagogia da pergunta de Freire se coloca como possibilidade de libertação de uma educação bancária numa cultura marcada pelo colonialismo em todos os campos da experiência. Assim, consideramos estas referências centrais para o tratamento de nossa problemática.

\section{A pergunta na prática de Sócrates}


A experiência mais significativa da filosofia como pergunta é realizada por Sócrates. É uma experiência paradoxal, porque o perguntar foi fatal para Sócrates acusado de "corromper os jovens", ao mesmo tempo em que ele afirmou que jamais foi mestre de alguém (Platão, 2008a, 33a). Como entender esta negação? O que ensina Sócrates? A princípio, ele não poderia ser condenado como o que sabe conduzir tal façanha, a corrupção da juventude, pois Sócrates declara que não sabe, nem acredita ser possuidor da sabedoria, e, neste caso, não afronta nenhuma divindade (Platão, 2008a, 21d). Com este argumento, ele afirma a impossibilidade de ter sido mestre de alguém por não possuir conhecimento algum, de maneira que se alguém afirma que aprendeu com ele algo, em público e em privado, mente (Apologia 33b). Sócrates afirma que não ensina conhecimento algum, mas tem quem aprendeu com ele e, inclusive, chorou sua morte. E o que se aprende então com Sócrates?

Ele próprio afirma, no Banquete, que sabe alguma coisa. Quase no início do diálogo, diz que não sabe nenhuma outra coisa a não ser as coisas do amor (Platão, 2008b, 177d); e já quando chega a sua vez de fazer o elogio a Eros, conforme proposto por Fedro, conta que foi Diotima, uma sacerdotisa de Mantineia - portanto, mulher e estrangeira - quem lhe ensinou as coisas do amor (Platão, 2008b, 201d). De modo que Sócrates, sim, sabe pelo menos uma coisa, o amor, saber que aprendeu e lhe foi ensinado por uma mulher estrangeira que o interrogava com cuidado e detalhe (Platão, 2008b, 201e) enquanto o ensinava. Depois, Sócrates relata essa experiência de aprendizagem: amor interrogante. O que Diotima ensinou a Sócrates? O amor de pensar por perguntas junto a outros. É isso o que Sócrates sabe com paixão erótica, e é isso que se aprende com a personagem de Sócrates: o amor às perguntas que nos leva a pensar com outros. Assim, a pergunta é um acontecimento social. Por um lado, o aprender a perguntar é acompanhado de um ato de amor iniciado de fora. No caso de Sócrates tem dupla exterioridade, a da estrangeira e da mulher. Aprender a amar a pergunta implica em desistir da verdade para caminhar com a incerteza, a dúvida, a flexibilidade que foge a qualquer reificação do pensamento. Por 
outro lado, a pergunta continua a sedução do amor que provoca o encantamento.

Platão, por meio de seu personagem Sócrates, no diálogo Teeteto (Platão, 2008c, 155d), identifica a atitude de espanto ou perplexidade como o começo da filosofia. A relação do espanto com a origem da filosofia é explicada por Sócrates aludindo a uma curiosa genealogia do deus Taumas, nome que significa maravilhamento, assombro, perplexidade para sua filha Íris, personificação do arco-íris, que é a mensageira dos deuses. O arco-íris é a ligação entre a Terra e o céu. Uma possível interpretação permite relacionar a atitude de espanto, maravilhamento, assombro, perplexidade à divindade. A prerrogativa da divindade, na mitologia grega, é a posse da sabedoria. Assim, Teeteto está tomado pelo sentimento divino, encontrar-se no caminho da sabedoria, Iris revela que ele é filósofo. As perguntas abrem o caminho que leva à sabedoria. O espanto é causador da indagação para alcançar a sabedoria.

A pergunta é a matriz pedagógica perfeita para a filosofia na obra de Platão. E a filosofia não escapa às indagações platônicas. Esta matriz dá corpo aos diálogos de inquirição conduzidos pelo personagem Sócrates. Este toma para si, de maneira metaforizada, o célebre trabalho da parteira Fainarete, sua mãe. A ação de partejar do filósofo é sobre a alma. Ele faz nascer perguntas e, assim, cuida da própria saúde da alma. Como Sócrates parteja as ideias? Ele é o mestre das perguntas e isto caracteriza seu método, a maiêutica, método de refletir por perguntas que provoca o nascimento de si, o engendramento do pensamento e o rompimento das correntes que mantém os homens de sua época presos à caverna, impedindo-o de partejar de seu próprio nascimento. O que desejamos salientar aqui, na impossibilidade de uma análise minuciosa do questionamento socrático como fator originador da filosofia em contraposição à leitura que enquadra Sócrates como mero sofista ateniense, é que seu modo de filosofar fazia uma revolução na sociedade grega pela pergunta. Sócrates é a pergunta que desnuda a tragédia ateniense, por vezes de forma muito cômica. Com certa extensão, ele trata da própria tragédia humana com os conceitos não pensados e que causam a cegueira na pólis. 
As perguntas de Sócrates despertam em Teeteto a perplexidade, a vertigem, o espanto, porque elas instauram o conflito no seu espírito e, pela reflexão, ele começa a descobrir a verdade velada nos ensinamentos dos mestres de seu tempo. O Sócrates dos diálogos de Platão continua interpelando os vivos, e enseja destas novas perguntas, começos do filosofar. Pois que outra missão Sócrates se propõe senão seguir o oráculo de Delfos: "Conhece-te a ti mesmo?" E que outro caminho temos para nos conhecermos senão o das perguntas? E como conhecer a si mesmo senão indagando àqueles que determinam a vida social dos atenienses?

A inquirição dialógica de Sócrates inaugura uma forma inovadora de filosofar com impacto político e educacional. A pergunta que engendra o diálogo tensiona a vida pública e se faz pedagogia para os que participam deste processo. A inquirição socrática se dá no espaço público e põe no centro da reflexão as afirmações dos homens famosos da aristocracia ateniense: generais, politicos, sacerdotes, educadores, legisladores, sofistas, filósofos etc. Assim, o filosofar por meio do diálogo inquiridor numa prática investigativa conduzida por Sócrates, ao eleger uma destas relevantes figuras da sociedade de seu tempo, põe em cheque a vida social grega: questiona e examina as falsas concepções em torno dos valores usados por estes líderes como condição para assumir um lugar de destaque na sociedade; denuncia e refuta as concepções inconsistentes de seu interlocutor e escancara a fraqueza de sua postura de vida e sua incompetência no exercício de uma função social na condução dos negócios da vida pública. A pergunta é profética: antecipa o destino da pólis ao evidenciar seus problemas e desafiar a busca de respostas.

O espaço público em que se trava o diálogo de Sócrates é composto também por uma plateia de discípulos que aprendem a arte do perguntar que cuida de esclarecer questões epistêmicas, éticas e políticas da vida civil. Os discípulos aprendem em meio a um diálogo que faz a crítica à cultura ateniense. Sócrates é a potência da pergunta. Colocando a dúvida, a controvérsia, a indagação reflexiva, o exame das crenças como razão da vida de uma criatura racional, denunciando a corrupção moral da aristocracia ateniense, ele foi sordidamente condenado à morte sob alegação de estar Interfaces da Educ., Paranaíba, v.10, n.30, p.414 - 438, 2019 
desprezando os deuses e corromper a juventude exatamente na medida em que libertava a juventude, sendo fiel ao oráculo de Delfos. Retornamos ao ponto fatal da pergunta: a condenação de Sócrates à morte é a condenação da pergunta à morte, o bloqueio do exame público, da investigação daquilo que está oculto nos discursos dos poderosos. Eliminando a pergunta, predominou na polis o discurso retórico que visa fixar uma certeza como forma de manutenção do poder.

Essa análise da experiência socrática com a pergunta como fonte da filosofia serve também para projetar luzes para compreender o que ocorre com a filosofia em nosso contexto de ensino atual. Em nossa perspectiva de análise, a filosofia sofreu uma profunda transformação de sua prática na Paidéia grega: tendo nascido como amor à pergunta, como busca da significação para a vida na polis, ela foi se fixando como amor à sabedoria ou amor às ideias, às teorias, aos sistemas filosóficos, àquelas significações que se fixaram como filosóficas, gerando um "enfeitiçamento" do pensamento. Neste movimento, a filosofia deslocou sua habitação do lugar do perguntar para o da reprodução das respostas, ou das próprias perguntas cujas respostas já se encontram prontas como verdades e não passiveis de crítica ou refutação. Neste caso, perguntas e respostas fechadas falseiam a filosofia como se a mão direita da certeza aquietasse os questionamentos da mão esquerda. A filosofia ficou refém da filosofia como uma atitude expectadora de si mesma, contemplativa de seus dogmas, um saber positivo a ser guardado na memória. Uma filosofia enfeitiçada por si mesma, enredada nas regras que criou e que a torna acessivel a poucos eleitos. Diante deste cenário, destacamos a crítica de Wittgenstein à metafísica e a necessidade de uma virada da atividade filosófica ao seu trabalho de pensar a linguagem, conforme postula o autor das Investigações filosóficas, no parágrafo 109, “A filosofia é uma luta contra o enfeitiçamento do nosso entendimento por meios da linguagem" (WITTGENSTEIN, 1975, p. 58).

Chamamos a atenção para este deslocamento da filosofia da sua força vital, a pergunta, para sua força material, o conceito, a verdade firmada racionalmente. O abandono do perguntar como fonte do filosofar e a fixação nas respostas dos filósofos erigiu uma história da filosofia que se Interfaces da Educ., Paranaíba, v.10, n.30, p.414 - 438, 2019 
torna quase que um estatuto da própria filosofia. O questionamento se tornou propriedade deste ou daquele pensador. É algo passado, dado na história; resta-nos repetir estas perguntas e respostas. O encastelamento no conceito criado, sistematizado, sacralizado como clássico, transformou a filosofia numa complexa elaboração de conhecimentos e métodos como se ela fosse uma ciência, a ciência do conceito, ou mesmo a ciência da verdade. Assim, historicamente a filosofia se converteu num domínio técnico, como se ela pudesse ser um sistema de saberes a ser ensinado ou a ser utilizado para fundamentar o próprio conhecimento ou uma autoridade pedagógica, retirando dela a sua força vital que é o questionamento sobre a experiência. Este enredamento da filosofia nas conclusões criando um universo de objetos abstratos pertencentes a si próprios sem contato com a experiência de vida ordinária, significa a submissão da filosofia ao que ela nega de si mesma por pelo menos dois motivos: primeiro, porque a retomada das mesmas questões ao longo da história da filosofia mostra que as respostas dadas são insuficiente, parciais, fracas, provisórias, controversas, refutáveis; segundo, sendo a filosofia fruto de seu tempo, mesmo colocando as mesmas questões de outrora, ela o faz sob a ótica das mudanças históricas, sociais, culturais e subjetivas que atravessam a experiência e exigem novo pensar e não mais a repetição de um mapa antigo.

Esta ênfase no fazer filosofia como um devir-pergunta resgata o valor da experiência como campo de problematicidade da qual a reflexão parte e para o qual deve retornar com resultados que tornem mais significativo, lúcido e autônomo o direcionamento do curso da experiência humana.

\section{Pergunta e pensamento reflexivo para Dewey}

A filosofia da experiência desenvolvida por John Dewey pode nos oferecer contribuições significativas nesta direção. Sua filosofia pode ser interpretada como um "desenfeitiçamento" da própria filosofia. Por um lado, sua análise (DEWEY, 1951) guiada pelo "método genético" de caráter experimental, faz duras críticas ao comprometimento da filosofia em sua história com uma tarefa de legitimação da ordem política na medida em que a razão é usada para organizar, justificar e fixar as crenças e cultos que 
mantém o poder dominante na sociedade. Estas filosofias colimaram nos dualismos que delimitam e separam as classes sociais entre as que pensam e as que trabalham, entre a teoria e a prática, entre sujeito e objeto. Neste caso, a formulação das perguntas e respostas é prerrogativa da classe intelectual que, inclusive, define a forma de transmissão e absorção das perguntas e respostas pelas classes trabalhadoras. Neste sentido, os dualismos fazem com que a realidade e a cultura sejam experienciadas de forma fragmentada.

Este pensador da experiência, defende que a filosofia deveria ser reconstruída como crítica aos dualismos e ocupar-se com a investigação dos problemas originários da experiência, ou seja, problematizar e pensar reflexivamente os mais profundos conflitos e as infindas incertezas da vida da civilização. Isto porque a experiência diária está impactada e fragmentada por um emaranhado complexo de hábitos e crenças herdados na transmissão da cultura. Quando as crenças não são inspecionadas criticamente, e entram em novos contextos de experiência, elas se convertem em preconceitos, mesmo tendo sido elaborados no campo da filosofia ou das ciências. Nesta perspectiva, a primeira tarefa que este autor atribui à filosofia pode ser colocada desta forma: "Sua primeira incumbência é clarificar, emancipar e estender os bens inerentes às operações da experiência naturalmente originada" (DEWEY, 1958, p. 407). Esta tarefa de clarificação e emancipação é desenvolvida pelo pensamento reflexivo que produz os conceitos - significações - que são os bens da experiência. Estas significações são formadas e organizadas por meio da linguagem, instrumento privilegiado da interação de um indivíduo com os outros membros num contexto de experiência compartilhada. Aqui, cabe trazer à tona a articulação que este pensador faz entre a dimensão da experiência e o discurso: "Um universo de experiência é condição prévia de um universo de discurso.” (DEWEY, 1960, p. 68). Parafraseando, a relação pode ser estabelecida da seguinte maneira: um universo de experiência é condição prévia para um universo de perguntas. Desta maneira, à filosofia cumpriria esta tarefa de desenfeitiçamento da linguagem ou do discurso, no sentido de detectar os preconceitos formados pelas interpretações e classificações do Interfaces da Educ., Paranaíba, v.10, n.30, p.414 - 438, 2019 
passado, problematizá-los buscando clarificar, ampliar e emancipar os usos dos conceitos na própria experiência. Neste sentido, o papel do filósofo é examinar criticamente as crenças que aparecem na forma de hábitos na experiência imediata. Mas o autor alerta para a dificuldade desta tarefa:

Uma filosofia empírica é, de qualquer modo, algo como despirse intelectualmente. Não podemos nos despojar permanentemente dos hábitos intelectuais que contraímos e vestimos quando assimilamos a cultura de nosso tempo e de nosso lugar. Mas o progresso inteligente da cultura exige que abandonemos alguns desses hábitos, que os inspecionemos criticamente, a fim de descobrir sua constituição e seu uso para nós. Não podemos retornar à primitiva ingenuidade. Não obstante há uma ingenuidade cultivada dos olhos, dos ouvidos e do pensamento, a qual é atingivel, mas só pode ser adquirida através da disciplina de um pensamento rigoroso (DEWEY, 1958, p. 37).

Dewey atribui um papel emancipador à filosofia na medida em que seu trabalho é empírico, ou seja, a inspeção crítica dos hábitos adquiridos na assimilação da cultura de forma que crie possibilidade de autocorreção deles. A experiência carrega um passado que precisa ser depurado num presente problemático tendo em vista um futuro a ser inventado e construído pela ação do próprio sujeito. Cultivar hábitos irreflexivos é perpetuar a ingenuidade do olhar, ouvir, pensar que ofusca e distorce a experiência. Hábitos irreflexivos são hábitos que impõem rotina (inclusive o ensino de memorização de perguntas e respostas), impedem o questionamento, eliminam a possibilidade de mudança e crescimento. Dewey valoriza os hábitos rotineiros que economizam energias do organismo na interação com o meio. Neste caso, interação não é adaptação. Isto quer dizer que nem tudo em nossa experiência deve ser perguntado, como sugere a dúvida metódica cartesiana que figura como trampolim para a certeza. A pergunta surge quando a interação - curso de uma ação - é bloqueada criando a situação problemática. A solução reflexiva de uma situação problemática permite a adaptação do sujeito ao meio. Vamos analisar mais detalhadamente este ponto.

O trabalho da filosofia, como pensar reflexivo sobre a experiência, consiste de inspecionar estas crenças ou hábito. Diz o autor: "O pensamento reflexivo faz um ativo, prolongado e cuidadoso exame de toda crença ou 
espécie hipotética de conhecimento, exame efetuado à luz dos argumentos que a apóiam e das conclusões a que chega." (DEWEY, 1979a, p. 18, itálicos do autor). O pensar reflexivo surge quando as crenças se tornam problemáticas, ou seja, quando um curso de experiência é interrompido pela dúvida, gerando a pergunta: "[...] uma pergunta a responder, incerteza a esclarecer, apresenta um objetivo à nossa reflexão e canaliza em determinado álveo a correnteza das idéias. (...) A natureza do problema a resolver determina o objetivo do pensamento e este objetivo orienta o processo do ato de pensar. (DEWEY, 1979a, p. 24, itálicos do autor).

O processo de pensar perguntando não se esgota na solução de um problema. As soluções circunstanciais tornam-se instrumento para novas indagações, alimentando indefinidamente o processo inquiridor. $\mathrm{O}$ autor enfatiza a relação entre dúvida e pensar:

Uma vez que o ato de pensar surge em situação em que existe dúvida, esse ato é um meio de investigar, de inquirir, de perquirir, de observar as coisas. Adquirir é sempre um ato secundário, e sempre serve de instrumento para o ato de inquirir. Este é uma procura, uma pesquisa daquilo que não se acha à mão. (...) todo o ato de pensar é investigação, é pesquisa e pesquisa pessoal, original, da pessoa que o faz, mesmo que todo o resto do mundo já conheça aquilo que ela procura descobrir. (DEWEY, 1979b, p. 162, itálicos do autor).

Sua crítica dirige-se àquelas concepções que tomam o pensamento como "caso de combustão espontânea." (DEWEY, 1979a, p. 24), ou, ainda, que entendem ser o pensar "[...] máquina de um salsicheiro, a qual reduz indiferentemente todos os materiais a um mesmo produto estereotipado para o comércio." (DEWEY, 1979a, p. 54). A crítica do autor dirige-se também às concepções que apartam, depreciam ou condenam a experiência, criando um dualismo entre pensar e agir, teoria e prática. O excerto ressalta o valor do pensar filosófico a partir do objeto concreto problemático da experiência primária e não de problemas criados artificialmente:

A referência à prioridade e à ulterioridade do material da experiência ordinária protege-nos, em primeiro lugar, de criar problemas artificiais que desviam a energia e a atenção do filósofo dos problemas reais que surgem a partir do objeto atual. Em segundo lugar, fornece um meio de conferir ou testar as conclusões da investigação filosófica; lembra-nos que precisamos fazê-la voltar como produtos reflexivos secundários, à experiência da qual provêm, de modo a serem Interfaces da Educ., Paranaíba, v.10, n.30, p.414 - 438, 2019 
confirmadas ou modificadas a partir da nova ordem e da clareza que consigam introduzir, e a partir dos novos objetos experienciados significativamente para os quais elas sejam capazes de fornecer método. Em terceiro lugar, pela observação de como funcionam em subseqüentes experiências, os produtos filosóficos adquirem eles próprios valor empírico; passam a ser aquilo que representam em termos de contribuição para a experiência comum do homem, em vez de curiosidades a serem exibidas, com os devidos rótulos, em algum museu metafísico. (DEWEY, 1958, p. 18).

Dewey valoriza o papel da filosofia no processo de transformação da experiência pela reflexão que, por sua vez, significa também a transformação da filosofia. Reconstruir a filosofia por meio de um filosofar que assuma a tarefa de pensar as perguntas da experiência-vida e, assim, assuma a responsabilidade com o desenvolvimento do potencial da experiência comum situada histórica e socialmente.

Este filosofar se faz necessário uma vez que a solução de um problema ao provocar mudanças no ambiente e no sujeito exigindo deste a reflexão para reorganizar logicamente os significados gerando um acúmulo de "asserções" ou juízos como aprendizado (método) que lhe servirá para tratar reflexivamente situações vindouras. Por outro lado, tais mudanças engendram novos problemas o que requer do sujeito um permanente perguntar e investigar:

A investigação, ao restabelecer a situação de distúrbio entre organismo e ambiente (que define a dúvida) não se limita a remover a dúvida, recorrendo a uma integração adaptativa anterior. Estabelece novas condições ambientais que originam problemas novos. O que o organismo aprende neste processo produz novos poderes que fazem novas demandas sobre $o$ ambiente. Em uma palavra, quando se resolvem problemas especiais, outros tendem a emergir. Não existe uma coisa como estabelecimento de solução final, porque todo estabelecimento introduz as condições de algum grau de indeterminação. (DEWEY, 1960, p. 35)

Nesta perspectiva, o processo de vida é inseparável do processo de perguntar. A pergunta é um meio de manutenção e continuidade da vida consciente e reflexivamente intencionada por diversas razões. Primeiro, a vida do organismo, na sua relação com o meio físico e cultural, é marcada pelo constante desequilíbrio de suas energias. Isto coloca o organismo numa luta pela recomposição do equilíbrio buscando as energias físicas e no seu meio natural, e imateriais no meio sociocultural. Este desequilíbrio, como Interfaces da Educ., Paranaíba, v.10, n.30, p.414 - 438, 2019 
por exemplo, a fome, guarda estreita relação com a pergunta. Esta aparece, neste primeiro nível da vida, conectada às necessidades básicas. É como se o organismo indagasse, sempre que submetido a um desequilíbrio, pela comida, pela proteção, pela temperatura adequada, pelo ar, pela água etc. Organicamente, o desequilíbrio de energia provoca a necessidade, desperta o esforço pela busca de satisfação, garantindo a continuidade da vida. Segundo, no caso de nossa espécie em que há interdependência entre os membros, essas necessidades são mediadas simbolicamente por meio da linguagem. As necessidades dadas no corpo são traduzidas de forma inteligente em perguntas por meio da linguagem. Neste interim, aprende-se a linguagem comum que abre as portas para inúmeros questionamentos toda vez que surge a necessidade de compreensão mútua das coisas do mundo comum. Nesta instância, desenvolve-se também a curiosidade e imaginação que ampliam infinitamente o campo de indagações. Terceiro, o aprendizado de uma experiência serve de recurso para lidar com novas experiências. Amplia-se a capacidade de aprender por meio do aprender a perguntar continuamente uma vez que ao responder uma pergunta ou resolver uma situação problemática a vida cresce qualitativamente com o acúmulo de aprendizados, mas também se defronta com novas dificuldades. Este processo cria condições do sujeito gerir e gerar seu crescimento na liberdade de traçar seu projeto de vida com consciência e responsabilidade na interação com a sociedade que participa. Quarto, a satisfação de algumas necessidades ou mesmo a busca de maneiras mais apropriadas de satisfazêlas, o ser humano cria outras necessidades - vale dizer perguntas - mais complexas cujos desdobramentos dão origem as especialidades da ciência, da arte, da religião e da filosofia.

Ressaltamos que para este autor o pensar é uma atividade inerente à vida desde sua origem. O desenvolvimento de um bebê atesta a atividade de pensar na medida em que ele resolve a seu modo (choro, balbucios, gestos) suas situações problemáticas. Seus primeiros problemas dizem respeito ao domínio de seu corpo para adaptar-se ao meio. A aquisição da linguagem na atividade compartilhada amplia incomensuravelmente a capacidade de pensar como ato social: "Por meio dela, em caráter de substitutos, 
conseguimos participar largamente da passada experiência humana, dilatando e enriquecendo assim a experiência presente. Achamo-nos habilitados, simbólica e imaginativamente, a antecipar situações. Por infinitos meios, a linguagem condensa significações que registram resultados sociais e pressagiam perspectivas sociais." (DEWEY, 1979b, p. 41). A aprendizagem da linguagem pela criança é alimentada pela criação de perguntas. Estas são sinal de que está havendo trabalho de pensamento. A aprendizagem se converte num processo de vida significativo quando o ato de pensar surge a partir das perguntas da experiência-vida da criança.

O pensar reflexivo como pensar inquiridor é um princípio educativo para Dewey. Diz ele: "Pensar é o método de se aprender inteligentemente, de aprender aquilo que utiliza e recompensa o espírito" (DEWEY, 1979b, p. 168, itálicos do autor). O pensar reflexivo se dá em torno de problemas da experiência. A reflexão guiada pela pergunta é o método de educar. Ressalta o autor a importância da experiência para despertar a reflexão investigativa: "O estágio inicial do ato de pensar é a experiência" (DEWEY, 1979b, p. 168). Esta é a condição de possibilidade para que as crianças possam colocar os problemas e se envolverem na investigação: " $E$ quando as crianças estão interessadas em fazer coisas e discutem a respeito daquilo que surge no curso desse fazer, verifica-se mesmo com métodos educativos relativamente sem valor, que suas perguntas e investigações são espontâneas e numerosas, e as soluções propostas, variadas e engenhosas. (DEWEY, 1979b, p. 171).

O processo de aprender a pensar reflexivamente dependerá da origem do problema como uma ruptura na continuidade da experiência da criança. Dewey deixa duas indagações que servem como critério para orientar a aprendizagem voltada para o desenvolvimento de hábitos reflexivos: "É a experiência uma coisa pessoal, de natureza própria a estimular e a dirigir a observação das relações existentes, e a conduzir a uma conclusão e à prova da mesma? Ou é imposta exteriormente e o problema do aluno o de simplesmente satisfazer a exigência de caráter exterior e compulsório?” (DEWEY, 1979b, p. 170). 
Quando o problema está genuinamente ancorado na experiência ela tem alcance social e se torna uma atividade compartilhada pela classe e pelo professor. Neste sentido, relação de aprendizagem se constitui num movimento de alternância entre professor e aluno: “Em tal atividade compartida, o professor é um aluno e o aluno é, sem o saber, o professor [...]" (DEWEY, 1979b, p. 176). O professor por sua vez participa da atividade como um mestre que indaga. O processo não é uma relação mecânica de perguntas e respostas. Exige uma arte de perguntar para movimentar a reflexão no processo investigativo. Dewey ressalta a importância da pergunta na condução do processo reflexivo: "A arte de perguntar é tão plenamente a arte de guiar a aprendizagem, que não se podem traçar regras rígidas e restritas para seu exercício. Uma pergunta sacode, esporeia a mente, forçando-a a ir até onde pode, melhor do que fariam os mais engenhosos artificios pedagógicos, se desacompanhado desse ardor intelectual" (DEWEY, 1979a, p. 262-263).

A arte de perguntar acompanha a arte de dialogar:

Uma discussão vital fará os problemas subjacentes se colocarem em foco bem definido. [...] a discussão deveria ser encaminhada de maneira que concentrasse o pensamento em uns poucos pontos essenciais, ao redor dos quais se organizassem outras considerações. Assim conduzida, a discussão induzirá o estudante a evocar e reexaminar o que aprendeu em suas experiências pessoais anteriores e o que aprendeu de outros (isto é, levá-lo-á a refletir) a fim de descobrir o que se relaciona, positiva ou negativamente, com o assunto do momento. Embora não se deva permitir que a discussão degenere em "bate-boca", uma discussão ardorosa mostrará as diferenças intelectuais, os pontos de vista e interpretações opostas, o que contribuirá para definir a verdadeira natureza do problema. (DEWEY, 1979a, p. 262263, itálico do autor).

Ressaltamos que para este autor a aquisição dos hábitos de pensar reflexivo e de discussão ou comunicação são formadoras do modo de vida democrático. As relações entre pergunta e democracia ensejam um debate aprofundado extrapolando, assim, o proposto para este texto.

Para este crítico, a educação tradicional ou escolástica está atravessada pela artificialidade e fragmentação. Ela divide a instrução em diversos fins cada um isolado dos demais, como, por exemplo, a aquisição 
das habilidades de ler, escrever, contar, desenhar, recitar etc., a aquisição de conhecimentos informativos como a história, geografia, ciências etc. A reflexão e o pensamento são considerados como mera decorrência deste ensino. A crítica do autor sobre a ênfase no processo de transferência e armazenamento do conteúdo é retratada nestes termos: "Toma-se em demasiada conta a acumulação e aquisição de conhecimentos com o intuito de sua reprodução no darem-se as lições, ou nos exames” (DEWEY, 1979b, p. 172). O problema da educação tradicional é o pouco espaço que as condições escolares reservam para a experiência pela própria estruturação da escola e das salas de aula. A quase ausência de perguntas pelos alunos sobre a lição denúncia esta maneira de instruir quando contrastado com a própria vida das crianças no ambiente extraescolar. Ele tece sua crítica desmascarando a realidade escolar:

O aparelhamento material e o aspecto de uma sala de aulas comum são adversos à existência das situações reais da experiência. Que existe aí de semelhante às condições da vida quotidiana, que possa ocasionar dificuldades e o desejo e a necessidade de vencê-las? Quase tudo comprava que o que mais se exige é ouvir, ler e reproduzir aquilo que foi dito e lido. Será dificil exagerar-se o contraste entre tais condições e as situações de contacto ativo com as coisas e pessoas, no lar, no campo de jogos ou ao satisfazer as responsabilidades do curso ordinário da vida. Muito do que se passa na escola nem mesmo se pode comparar em importância com as perguntas que surgem no espírito de um menino ou de uma menina conversando com outros meninos ou meninas ou lendo livros fora da escola. (DEWEY, 1979b, p. 170).

Dewey critica esta educação por apresentar problemas simulados, artificiais e, mesmo ridículos para os alunos. Tais problemas não são realmente dos alunos, ou são destes na condição de alunos e não de seres humanos. A aprendizagem fica falseada porque o interesse pelo problema do conteúdo passa a ser indireto uma vez que é redirecionado para o problema real e imediato da nota, pontuações, aprovação e promoção. O problema que está em jogo nesta relação é o de satisfazer as exigências do professor, saber o que este quer, atender suas exigências quanto ao dar lição, obter resultados nos exames e no seu comportamento em geral. Suas severas críticas a esta educação atenta para dois aspectos centrais da formação: a abordagem dos problemas contraria o pressuposto lógico ou epistemológico 
da investigação na construção do conhecimento como forma de resolver situações problemáticas da existência real dos homens e, psicologicamente, ao atochar indiscriminadamente o espírito do aluno com materiais diversos cria mais dificuldades para estes quando tentarem refletir; segundo, perverte o caráter dos alunos:

O aluno estuda, mas, sem disto ter consciência, os objetos de seu estudo são as convenções e modelos do sistema escolar e dá autoridade escolar e não os "estudos" em si mesmos. A reflexão assim provocada é, na melhor das hipóteses, artificialmente unilateral. $\mathrm{Na}$ pior, o problema do aluno não será o de satisfazer as exigências da vida escolar e sim o de aparentar satisfazê-las - ou o de avizinhar-se de sua satisfação o suficiente para deslizar sobre as mesmas sem muito atrito. A espécie de senso criada por estes expedientes não é um desejável elemento para a formação do caráter. (DEWEY, 1979b, p. 171).

O resultado disso é a naturalização de um sistema com regras e valores próprios aos quais todos (alunos e professores) devem se adequar em contraponto a uma educação promotora do crescimento da experiência, da aquisição do hábito de pensar, única maneira de aprender significativamente, ou seja, aprender reflexivamente, aprender pensando, aprender pela e para a experiência, aprender a aprender. Para Dewey, a educação tradicional trabalha a contrapelo favorecendo experiência deseducativa, segregadora, reprodutora de perguntas e respostas artificiais por não desenvolver as capacidades de problematizarão, reflexão, crítica e criatividade:

Será, talvez, demasiado afirmar que muitos estudantes julgam conscientemente serem coisas irreais as matérias dos estudos; mas é certo não possuírem estas para eles a mesma espécie de realidade que a matéria de suas experiências vitais. Não aprendem a encará-las como sendo desta espécie de realidade; habituam-se a considerá-las como tendo realidade para o fim de dar lições e de passar em exames. E admitem, pacificamente, que tais acontecimentos sejam inúteis e inertes para os atos da vida quotidiana. Dois são os maus efeitos que resultam. A experiência ordinária dos estudantes não adquire o enriquecimento que poderia ter; não é fecundada pelos estudos escolares. $\mathrm{E}$ as atitudes advindas de costumarem-se a isso de absorver material semicompreendido e semidigerido enfraquecem o vigor e a eficiência mentais. (DEWEY, 1979b, p. 176).

A educação tradicional transforma o estudante em espectador, acomoda sua curiosidade às perguntas que são legitimadas pela autoridade Interfaces da Educ., Paranaíba, v.10, n.30, p.414 - 438, 2019 
do professor. Assim, desaprende a perguntar e a dialogar. Faz de um infante questionador um adulto de cabeça cheia, ou cabeça feita de ideias fixas e acabadas. Esta íntima relação da pergunta com a vida faz a própria infância ser um mundo de perguntas para alimentar uma fala significativa, em contraposição a uma fala muda de sentido, ou da repetição de um saber inerte acumulado na memória. Infância como vazão da pergunta, da força interrogante que se move pelo espanto com o mundo, perplexidade e insatisfação com o estado de coisas que circundam a vida. A infância-pergunta é também uma brincadeira lúdica com o mundo, um amor pela descoberta, uma curiosidade transformadora. Assim, a pergunta constitui a mais original fonte do interesse como espanto pelo mundo, despertando a necessidade de interpretar o outro e dar sentido à experiência neste mundo. É possível uma escola para esta infância-pergunta? Que resultará dela diante de uma educação artificial, fragmentária, reprodutora, competitiva e individualista?

Considerando que o perguntar surge ligado à necessidade de lidar com aquilo que é de interesse vital na experiência e que esta tem caráter social, o processo de perguntar para aprender e um aprender para perguntar reveste-se de uma dimensão ética no sentido de ser um ato corajoso e livre na feitura do ser humano. Daqui podemos inferir que a melhor tradução do termo homo sapiens sapiens, usado para denominar a espécie humana é homo quaeritur, homem pergunta.

O homem nasce como pergunta. Não perguntamos ao cachorro o que ele vai ser quando crescer. Nem perguntamos a uma planta que fruto uma planta produzirá. Nem o cachorro nem a planta se perguntam quem serão. Perguntamos ao bebê: quem ele será? O homem nasce imaturo, como diz Dewey ou nasce inacabado, com diz Freire, porque nasce como ser de perguntas que direcionam a sua própria construção. A pergunta é o resgate da potencialidade do humano. A pergunta é uma força que arremessa o ser humano para além das limitações de seu cotidiano. Negar-se a perguntar é se deixar devorar sufocado pelas ideologias, verdades impostas, conceitos prontos. A pergunta se transforma num meio de fazer a crítica à cultura como forma de emancipar-se de tudo o que ameaça a própria dignidade, 
restringe, obscurece, inibe a experiência. A pergunta permite também buscar maneiras de recriar ou transformar a cultura.

\section{A pedagoga da pergunta de Freire}

A análise mais contundente da experiência castradora das perguntas em nossas escolas foi feita por Paulo Freire. A escola do conteúdo, bancária, verbalista é uma escola da opressão à pergunta. Ele é enfático em mostrar o autoritarismo em relação à pergunta:

[...] o autoritarismo que corta as nossas experiências educativas inibe, quando não reprime, a capacidade de perguntar. A natureza desafiadora da pergunta tende a ser considerada, na atmosfera autoritária, como provocação à autoridade. E, mesmo quando isso não ocorre explicitamente, a experiência termina por sugerir que perguntar nem sempre é cômodo. (FREIRE, 1985, p. 46).

A repressão à pergunta é repressão ao próprio pensar ou ao dizer a palavra autêntica, é uma forma de invasão do espaço de reflexão do outro. Para Freire, a pedagogia do oprimido passa necessariamente pela pedagogia da pergunta, requer o contínuo problematizar a experiência de opressão, indagar por outro projeto de homem e sociedade e desencadear uma ação transformadora sempre guiada pela pergunta e pelo diálogo.

Freire, partindo da constatação histórica da realidade brasileira, ressalta a inexperiência democrática, que não deixa de ser uma inexperiência de diálogo e pergunta, que sustenta a estrutura opressiva da sociedade brasileira desde sua origem. A educação bancária contribui para gerar pessoas não dialógicas, não problematizadoras e, portanto, não democráticas. Elas se tornam hospedeiras do saber opressor, o saber das elites. A superação desta realidade opressora historicamente criada e por isso possivel de ser transformada se faz possivel por meio da problematização: "É que, na problematização, cada passo no sentido de aprofundar-se na situação problemática, dado por um dos sujeitos, vai abrindo novos caminhos de compreensão do objeto da análise aos demais sujeitos” (FREIRE, 1980, p. 82). O objeto de análise problematizado, diz Freire (1980, p. 82). "[...] é inseparável das situações concretas. Esta é a razão pela qual, partindo destas últimas, cuja análise leva os sujeitos a 
reverem-se em sua confrontação com elas, a refazer a confrontação, a problematização implica um retorno crítico à ação. Parte dela e a ela volta."

A problematização é um processo que tira as pessoas do isolamento e cria uma relação intersubjetiva por meio do pensar e comunicar coparticipado:

O sujeito pensante não pode pensar sozinho; não pode pensar sem a co-participação de outros sujeitos no ato de pensar sobre o objeto. (...) Esta co-participação dos sujeitos no ato de pensar se dá na comunicação. (...) O que caracteriza a comunicação enquanto esse comunicar comunicando-se, é que ela é diálogo, assim como o diálogo é comunicativo. (FREIRE, 1980, p. 66, grifos no original).

Freire esclarece sua concepção educativa dizendo que ela "[...] gira em torno da problematização do homem-mundo. Não em torno da problematização do homem isolado do mundo, nem da ênfase deste sem aquele, mas de relações indicotimizáveis que se estabelecem entre ambos" (FREIRE, 1980, p. 83). Daí que para ele, a problematização não pode ser um fuga da ação, um disfarce ou negação da realidade, um jogo intelectualista. A problematização impede que a educação se transforme em dissertar, discursar, narrar, falar, transferir saberes, fazer comunicados que manipula e neutralizam o pensar, favorece à ingenuidade e não à conscientização e libertação na medida em que o outro é transformado em um paciente, ou um objeto da recepção. Assim, a educação problematizadora é um processo dialético que exige o comprometimento com o problema: "Ninguém, na verdade, problematiza algo a alguém e permanece, ao mesmo tempo, como mero espectador da problematização" (FREIRE, 1980, p. 82). Reunindo estes aspectos, a educação como situação gnosiológica deve ser dialógicaproblematizadora:

[...] põe-se diante de si mesmo. Indaga, pergunta a si mesmo. E, quanto mais se pergunta, tanto mais sente que sua curiosidade em torno do objeto do conhecimento não se esgota. Daí a necessidade de ampliar o diálogo como uma fundamental estrutura do conhecimento - a outros sujeitos cognoscentes. (FREIRE, 1980, p. 67)

Para Freire, a pergunta e o diálogo conjugam a dimensão epistemológica e ética tendo em vista uma transformação do mundo concreto em que os homens vivem, articulando-se assim com uma dimensão política. 
Gerar este movimento de aprender a perguntar, de questionar a realidade opressora é criar um processo de libertação, porque acompanhado da responsabilidade e a autonomia dos sujeitos que, respeitando suas diferenças, se envolvem dialógica e dialeticamente na transformação do mundo, na humanização, na busca do "ser mais" daquela condição de seres inacabados, inconclusos, finitos. Os problemas surgem do assumir estas condições somadas à dimensão de seres temporalizados, condicionados, mas não determinados, relacionados com outros sujeitos que se encontram também em processo de busca de sua libertação. A pergunta é desencadeadora da libertação pelo pensar reflexivo e pelo diálogo, que criam a possibilidade de dizer a palavra verdadeira, conjugando ação e reflexão:

A existência, porque humana, não pode ser muda, silenciosa, nem tampouco pode nutrir-se de falsas palavras, mas de palavras verdadeiras, com que os homens transformam o mundo. Existir, humanamente, é pronunciar o mundo, é modificá-lo. O mundo pronunciado, por sua vez, se volta problematizado aos sujeitos pronunciantes, a exigir deles novo pronunciamento (FREIRE, 2014, p. 108).

Em Freire, a pergunta representa um processo reflexivo-dialógico de transformação da experiência histórica de homens e mulheres, ou experiência libertadora. Neste sentido, a pergunta articula diversas dimensões da experiência humana: a política na medida em que ação e reflexão pela libertação se constituem em prática democrática; a ética, na medida em que implica relações permeadas por valores como a solidariedade, amor, esperança em torno do projeto partilhado entre os sujeitos; a epistêmica, na medida em que se faz curiosidade crítica problematizando os conhecimentos (científicos, técnicos e experimentais) na busca pela compreensão, explicação e transformação da realidade concreta.

\section{Considerações finais}

Consideramos que a tarefa social e política da filosofia é pensar os problemas humanos de cada tempo e lugar. A infância e a sua educação se tornaram problema filosófico central em nosso mundo que quer roubar a experiência da pergunta iludindo com produtos de sofisticada tecnologia que dão satisfação imediata. Como problemas filosóficos são aqueles que atingem 
todas as pessoas, consideramos que o caminho para os enfrentar é também filosófico, requer engajamento, compreensão e construção conjunta da cultura do pensar por pergunta numa educação escolar voltada para a criticidade.

Em certa medida, as práticas educacionais atuais ainda estão enredadas na educação tradicional, como mencionamos seguidamente em nossa discussão. Diversos mecanismos impedem uma educação pela pergunta: livros didáticos, provas e exames (desde a sala de aula, passando por exames regionais, nacionais e até internacionais), a formação de professores etc. A educação tradicional criou um sistema fragmentário e maquinal de perguntas e respostas chamando-o de transposição de conhecimentos com belos nomes como "tradição", "conteúdos" e outros. A experiência da criança fica relegada abaixo do limiar da racionalidade ou da memória e, quando acionada é apenas para confirmar aquilo que está previamente definido. A educação se transforma numa fórmula de reprodução, numa rotina de ouvir e escrever o ditado, num jogo obscuro, falso e fechado de perguntas e respostas que serve para dar nota, pontuar, classificar, premiar e autorizar alguns que seguem adiante enquanto muitos sucumbem. Estes são desclassificados pelo sistema, não necessariamente porque não sabem, mas porque o sistema não quer saber deles, de suas perguntas, de suas inquietações. A experiência da pergunta se transforma em experiência-vencedor, ou experiência-perdedor ou ainda experiênciamorte. Assim, o trabalho fragmentário de perguntas e respostas contribui com uma experiência-morte da filosofia e educação.

Ilustrativo é o preconceito em relação às perguntas dos alunos na medida em que elas são julgadas como "perguntas da moda", perguntas que estão influenciadas pelo senso comum ou pela ideologia dominante. Neste caso, pressupõe-se que o professor fica refém e reprodutor desta ideologia, ou quando não na "mesmice" remissiva às próprias perguntas, perdendo seu precioso tempo para dar conta de trabalhar o conteúdo. Esquece-se aqui que as perguntas são sempre pontos de partidas numa caminhada que não finda. Neste sentido, quando mais expressam o modo de pensar dominante, das ideologias em voga, do senso comum tanto mais pertinentes para a Interfaces da Educ., Paranaíba, v.10, n.30, p.414 - 438, 2019 
reflexão, para o desenvolvimento da crítica, inclusive sobre a própria pergunta. Ou será que pensamento crítico é algo dado pronto num conteúdo ensinado de cima para baixo, mormente uma filosofia, ou numa pergunta dada para o outro responder? Não podemos fazer o pensar crítico cooperar com o aprender a perguntar?

Aprender a perguntar, ou reaprender a perguntar torna-se uma questão central para quem realmente deseja filosofar, como processo de emancipação da condição de menoridade para a de uso do entendimento, na ótica kantiana. Por um lado, cabe fazer a crítica à cultura do perguntar na educação e na escola. Resistir à padronização do pensar por perguntas prontas. Por outro, redescobrir na pergunta a própria experiência existencial. Fazer filosofia é interrogar a experiência humana no mundo, questionar as crenças e nosso próprio pensamento. As perguntas genuínas são extensão de nós mesmos e consistem num trabalho de transformação e crescimento sobre si mesmo. A eclosão da reflexão filosófica pelas perguntas cria a possibilidade de uma autoeducação, da autoconstrução, da formação de um ser consciente de si.

A pergunta é a força motriz da atividade do pensamento em busca da construção reflexiva dos sentidos da experiência. Assim, no perguntar está o vigor do filosofar. Ela constitui a mais original fonte do interesse porque se liga à necessidade de interpretar o mundo e dar sentido à experiência. Além disso, o ato de perguntar é um ato coragem no uso da liberdade. Ela faz com que a pessoa tome consciência do seu direito de indagar e exerça seu poder de decidir rever as crenças em função das mudanças da realidade, suspeitar das certezas estabelecidas em busca de explicações mais satisfatórias para os problemas que surgem na vida. Assim, a liberdade de perguntar vai se ampliando na medida em que se desperta a sensibilidade para os aspectos problemáticos da experiência criando também a responsabilidade para desenvolver um projeto de inquirição como forma de transformar a realidade de insatisfação diante dos desafios, ou seja, buscar novas explicações, definir e clarificar os conceitos, resolver os problemas que nos tocam.

Um questionamento realmente intrigante, prenhe de um problema vital, exige o diálogo na busca dos significados da experiência construídos num 
esforço comum. Desenvolver o hábito de perguntar mantém viva a investigação na medida em que os conhecimentos se colocam como provisórios e sujeitos a novas indagações. Cria-se, assim, a atitude reflexiva e investigativa, expressa no processo de perguntar-responder-perguntar. Aprender a perguntar é um caminho para aprender a filosofar criticamente sobre a experiência para desenfeitiçar a linguagem da opressão, desnaturalizar os determinismos que geram ação rotineiras, automatizadas e alienadas. Neste sentido, a indagação filosófica é uma condição para a vida democrática que requer do cidadão a participação crítica e criativa na solução dos problemas comuns. Perguntar é também um filosofar criativo sobre a experiência, construindo significados geradores de processos de transformação e libertação. O perguntar constituiu o que é genuinamente humano. A continuidade do processo de humanização está dependendo da capacidade de interrogar. Respostas são motivações para a indagação.

\section{Referências:}

DEWEY, John. Como pensamos como se relaciona o pensamento reflexivo com o processo educativo: uma reexposição. Tradução: Haydée Camargo Campos. $4^{a}$ ed. São Paulo: Nacional, 1979a. Atualidades pedagógicas; vol. 2. - Democracia e educação. Tradução: Godofredo Rangel e Anísio Teixeira. São Paulo: Nacional, 1979b. Atualidades pedagógicas; vol. 21. . Experience and nature. New York: Dover Publications, Inc., 1958. . Logic. The theory of inquiry. New York: Henry Hold and Company, 1960.

. Reconstruction in philosophy. New York: Mentor Books, 1951.

. The quest for certainty: a study of the relation of knowledge and action. 12 ed., New York: Minton, Balch \& Company, 1929.

FREIRE, Paulo. Extensão ou Comunicação? Paz e Terra. Rio de Janeiro, 1980.

. Pedagogia do oprimido. 56 ed. Rio de Janeiro: Paz e Terra, 2014.

FREIRE, P.; FAUNDEZ, Antonio. Por uma pedagogia da pergunta. Rio de Janeiro: Paz e Terra, 1985. 
PLATÃO. Apologia de Sócrates. Tradução de Edson Bini, Bauru: SP, EDIPRO, 2008a.

PLATÃO. O banquete. Tradução de Edson Bini, Bauru: SP, EDIPRO, 2008b.

PLATÃO. Teeteto. Tradução de Edson Bini, Bauru: SP, EDIPRO, 2008c.

WITTGEnSTEIN, L. Investigações Filosóficas. São Paulo: Abril Cultural, 1975. 